\title{
An exploratory genre analysis of three graduate degree research proposals in applied linguistics
}

\author{
Bin Yin (D)
}

\author{
Correspondence: \\ yin.bin@hotmail.com \\ Nanyang Technological University \\ National Institute of Education, \\ Singapore, Singapore
}

\begin{abstract}
This exploratory study investigated the rhetorical structure of three research proposals written by students who successfully sought entry into MA/PhD programs in applied linguistics at a Singapore university. Despite the abundance of research on published academic texts (such as the research article), not much is known about research proposals written for degree admission purposes, which are identified as an occluded genre. Following the Swales tradition of genre analysis, the proposals were analyzed in terms of their rhetorical "move" structure, complemented by interviews with the proposal writers and one expert informant to elicit contextual factors such as intended readership, authorial positioning, and institutional expectations for this genre. The results show that the rhetorical structuring and the realization of moves were shaped by the communicative purpose of research proposals and disciplinary expectations. Differences between subfields of applied linguistics can be seen in the presence/absence of moves such as those related to proposed methodology. While exploratory in nature, this study sheds light on an important, occluded genre, with pedagogical implications.

Keywords: Genre analysis, Academic discourse, English for Specific Purposes, Research proposals, Occluded genre, Applied linguistics
\end{abstract}

\section{Introduction}

The study of academic discourse in its various aspects has attracted much attention in genre analysis over the past two decades, to make explicit the values upheld and practices endorsed in various academic communities (Samraj 2004). The academic genres that have been investigated include various types of published texts, such as the much valorized research article (RA) (e.g., Swales 1990; Anthony 1999; Samraj 2002; Yang and Allison 2003; Lin and Evans 2012; Martín and León Pérez 2014), dissertations (e.g., Hopkins and Dudley-Evans 1988; Bunton 2002; Kwan 2006; Thompson 2009), data commentaries, research reports, abstracts and posters (Swales and Feak 1994, 2000). However, research proposals written for entry into degree programs as an exemplar of occluded genres (Swales 1996) have so far not been looked into, partly due to the lack of access to this type of texts. Nonetheless, the importance of the research proposal as a means to gauge the competence of students and its gate-keeping role in selecting future players in the academic world is clear. This exploratory study investigated three research proposals written by successful applicants to $\mathrm{MA} / \mathrm{PhD}$ programs in applied linguistics

(c) 2016 The Author(s). Open Access This article is distributed under the terms of the Creative Commons Attribution 4.0 International License (http://creativecommons.org/licenses/by/4.0/), which permits unrestricted use, distribution, and reproduction in any medium, provided you give appropriate credit to the original author(s) and the source, provide a link to the Creative Commons license, and indicate if changes were made. 
at a Singapore-based university. The study seeks to account for the rhetorical structure of the graduate degree research proposal in terms of its communicative purpose, institutional expectations and represented disciplinary culture. In the next section, I look in more detail at the Swalesian tradition of academic genre analysis, focusing on the CARS model (Creating a Research Space) and discussing its applications and adaptations. Then, I argue for the importance of examining the graduate degree research proposal as a genre.

\section{Genre analysis of academic discourse in English for Specific Purposes (ESP)}

Genre analysis of academic texts can operate at both micro and macro levels. At the micro level, researchers examine the way certain grammatical or lexical features are employed in writing, such as the use of hedging, modality and reporting verbs (Thompson and Ye 1991; Salager-Meyer 1992; Hyland 1996), metadiscourse markers (Hyland 2008), and lexical verbs (Williams 1996). At the macro level, especially within the English for Specific Purposes (ESP) tradition, researchers deal with the patterns of rhetorical organizations of academic texts in various disciplines. The rhetorical organization of a text is often described as being made up of series of rhetorical "moves", defined as a segment of text that is shaped and constrained by a specific communicative function (Holmes 1997). Therefore, when a stretch of text is identified as containing a coherent rhetorical function, it will be analyzed as a move whose labeling unambiguously indicates its function. Within each move there are one or more further realizations known as "steps" or "strategies". These functional components (moves, steps or strategies) can be identified for each genre and such knowledge (e.g., presence, absence, and sequence of components) can then be used in the context of ESP instruction.

The most prominent model for rhetorical moves analysis is Swales (1990)'s Creating a Research Space (CARS) invented to capture the rhetorical content of research article introductions (see Table 1). As seen in Table 1, Move 1 Establishing a territory is realized by three strategies: Claiming centrality, Making topic generalizations and Reviewing items of previous research. The other two moves: Establishing a niche and Occupying the niche are likewise realized by further steps. The labeling of the moves in CARS

Table 1 Swales' CARS model (adapted from Swales 1990, 141)

\begin{tabular}{cc}
\hline Move one & Establishing a territory \\
Step 1 & Claiming centrality and/or \\
Step 2 & Making topic generalization(s) and/or \\
Step 3 & Reviewing items of previous research \\
Move two & Establishing a niche \\
Step 1A & Counter-claiming \\
Step 1B & Indicating a gap \\
Step 1C & Question-raising \\
Step 1D & Continuing a tradition \\
Move three & Occupying the niche \\
Step 1A & Outlining purposes \\
Step 1B & Announcing present research \\
Step 2 & Announcing principal findings \\
Step 3 & Indicating RA structure \\
\hline
\end{tabular}


reflects the persuasive nature of article introductions: namely, readers are being persuaded to accept the research being presented. Rhetorical analyses inevitably come with some degree of subjectivity (Crookes 1986). In cases where a sentence or a chunk of text could be analyzed as serving more than one rhetorical function (move or step), the conventional practice in the field is to assign the most salient move or step (Crookes 1986; Holmes 1997). Another important point to note is that the original model was based on RAs in the disciplines of sciences and engineering, but has since been applied and adapted for different genres and disciplines, resulting in further refinements or modifications to the model. Here, I briefly discuss some of the well-known adaptations of the CARS model in the literature (Anthony 1999; Samraj 2002; Bunton 2002).

Anthony (1999) was concerned with the extent to which the CARS model can accurately account for article introductions in software engineering. He noted three aspects of the model that need modification to accommodate his corpus of 12 papers. Specifically, many steps in CARS appear to be redundant for software engineering writing (e.g., Step 1-1, 2-1A, 2-1C, 2-1D, and 3-1A; see Table 1 for the steps). Second, papers in his corpus included definitions of key terms and concepts in their introductions, a strategy that is not accounted for in CARS. Lastly, most of the papers in the corpus utilized a rhetorical strategy whereby the paper authors evaluated the research being presented either with respect to the practical applicability or the novelty of the research. Anthony (1999) termed this strategy Evaluation of research and included this as a new step under Move 3 (Occupying the niche). The near obligatory presence of this step and its prominent proportion in Move 3 was explained by the central concerns of the field of software engineering (models being developed need to be applicable; and authors may also need to show uniqueness).

Samraj (2002) is another well-known adaptation of the CARS model whereby two related sub-disciplines within environmental science were examined in 12 RA introductions: Wildlife Behavior and Conservation Biology. First, it was found that Reviewing items of previous research (Step 1-3 in CARS) does not occur just in the first move, but can be embedded within other steps, such as gap-indicating (Move 2) or goal specification (Move 3). Therefore, Samraj $(2002,16)$ proposes removing Reviewing items of previous research as a step under Move 1, and instead treating it as a "free-standing sub-step that can be employed in the realization of any step in the introduction". Further, Samraj (2002) found that centrality claims (in Move 1) and gap indications (in Move 2) can be couched in terms of both the phenomenal (real) world or the epistemic (research) world. Here, disciplinary variations were detected: while Wildlife Behavior tends to employ rhetorical strategies referring to the epistemic world, Conservation Biology tends to emphasize issues in the real world. Samraj (2002) suggested that the variations were due to the fact that Wildlife Behavior is a theoretical, disciplinary field with an established historical depth whereas Conservation Biology is an applied, interdisciplinary area that was still emerging. These new insights, and others were incorporated into a modified CARS model in Samraj $(2002,15)$.

Lastly, Bunton (2002) adapted the CARS model for the analysis of $45 \mathrm{PhD}$ theses written by students from a variety of disciplinary fields at the University of Hong Kong. While using the same moves in the CARS model (and those in Dudley-Evans 1986), Bunton (2002) developed 10 additional steps, mostly for Move 3 (Announcing the present research or Occupying the niche). Some of the additional steps include Defining 
terms (Move 1), Method, Materials or Subjects, Product of research/Model proposed, Chapter structure and Theoretical position (all under Move 3). Bunton (2002) notes that, compared with research articles, $\mathrm{PhD}$ introductions are necessarily more elaborate, given their more extensive scope.

These, together with numerous other works drawing on the CARS model (e.g., applied linguistics, Kwan 2006; Ozturk 2007; sports science and medicine, Zeng 2009; agricultural sciences, del Saz Rubio 2011; management, Lim 2012) have both demonstrated the usefulness of CARS as a framework of rhetorical descriptions for academic texts, and shown the existence of variations in text types and disciplines (Samraj 2002; Ozturk 2007). Another point to note is that the RA remains the text type receiving the most attention in rhetorical genre analysis due to its status in the academic community as the vehicle of knowledge production and transmission, and therefore the lifeblood of the academy (Hyland 2000). Nevertheless, a discourse community necessarily engages in a plurality of genres (Bhatia 2002), and understanding texts beyond the research article is important to uncovering the discourse community's values and practices. In the two sections that follow, I discuss research proposals as an important, but occluded genre that forms part of the academic genre system.

\section{The research proposal as an occluded academic genre}

One important academic genre that has not been given due attention is the graduate degree research proposal (Swales 1996). It belongs to a group of "research process" texts written for a small-group audience (typically the admission committee), but may nonetheless be "seriously invested with demonstrated scholarship and . . representing their authors in a favorable professional light" (46). As a genre hidden from the public, existing studies on research proposals written for graduate admission purposes are practically non-existent, although there is research on related genres, such as grant proposals written by established or junior researchers (Connor and Mauranen 1999; Connor 2000; Myers 1990; Feng 2008; Cheng 2014) or proposals written by existing graduate students as part of their candidature advancement requirements (Cadman 2002). It is evidently important to understand this genre both for theoretical and pedagogical reasons. Besides being part of a genre system that constitutes a discipline's culture, research proposals serve an important gate-keeping role in higher research degree admission, and by implication, entry into the academic/discourse community. However, because the requirements for this genre are usually implicit, student applicants may have difficulties in matching their texts with the expectations of their targeted audience. This is especially so for students writing across linguistic and cultural boundaries, and who could therefore benefit from the findings of research into this occluded genre.

Given these, the present study investigated three graduate degree research proposals submitted by students applying for admission to a research degree program at a Singapore-based university. The objective of the study is to describe the rhetorical structure of the research proposals, how it relates to the communicative purposes and the expectations of the institutional context, and how the above facets may vary along disciplinary lines. Informed by current understandings of genre theory which stress the relationship between text and context (Swales 1990; Bhatia 1993), this study combines textual analysis of research proposals (rhetorical moves) with interview data from an expert informant as well as the authors of the proposals to achieve a 
preliminary understanding of research proposals in applied linguistics in a specific academic setting.

\section{Existing studies on research proposals}

In this section, I review existing genre studies on research proposals: Myers (1990), Connor and Mauranen (1999), Connor (2000), Feng (2008), Cheng (2014), Cadman (2002). The first five studies were actually on grant proposals, a type of research proposal written to request government or private funding. Only the last study by Cadman (2002) examined research proposals written by students for their degree programs and bears the closest resemblance to the present study.

As one of the earliest studies on the research proposal, Myers (1990) described grant research proposals as "the most basic form of scientific writing" (41) since researchers need to secure funds before engaging in their research projects. He studied drafts and final versions of two US biologists' research proposals and examined their writing processes through interviews and observations of their writing activities. Myers (1990)'s study highlighted the difficult balance that researchers try to strike between being original in their proposed research and being compliant with the existing body of literature in their field. Myers (1990) argues that the rhetoric of the proposal varies with each discipline (in this case, two subfields in biology) and also in terms of the researcher's relation to the discipline.

Compared with Myers (1990), Connor and Mauranen (1999)'s study of grant proposals is more textually grounded. Their study is concerned with the identification and description of rhetorical moves of grant proposals written by 34 established scientists from the European Union (EU). Drawing on the CARS model, the authors were able to identify 10 moves in the grant proposals: Territory, Gap, Goal, Means, Reporting previous research, Achievements, Benefits, Competence claim, Importance claim, and Compliance claim. Connor and Mauranen (1999) found that some of these moves, such as the competence and compliance claims are specific to grant proposals while others like Territory, Gap, and Means can be found in research articles as well. A follow-up study (Connor 2000) in the US context found that, compared with their European counterparts, US grant proposal writers tended to explicitly specify their research purpose by a Research question or Research hypothesis move. Connor (2000) speculated that this might be explained by stronger expectations about precise research question formulation on the part of American proposal reviewers, causing US researchers therefore to "pretend that their research is farther along than it actually is" (19).

While the studies reviewed above had been conducted in Western contexts, Feng (2008) took a comparative approach and examined the grant proposals written by nine social sciences/humanities Chinese scholars between 1996 and 2001. It was found that while the Chinese language proposals shared similarities with English language ones from a comparable study conducted in Canada (Feng and Shi 2004), stark differences emerged as well. For instance, in realizing the Niche move, while English language proposals offered detailed discussions and critiques of previous items of research, the Chinese language proposals provided vague criticisms on uncited work, which was interpreted as a practice of "face-saving". The Means (i.e., methodology) move in the Chinese proposals also lacked specificity compared with the English language texts, which was interpreted as reflecting a lack of understanding on empirical research methodology in the Chinese research community. 
Different from the above research on grant proposals by faculty members, Cheng (2014) looked at two US-based English as second language doctoral students' process of writing dissertation grant proposals for biophysics and musicology. Cheng (2014) studied proposal writing through the metaphor of "game-playing" - namely that academic writing involves the learning of rules and conventions, as well as repeated participation. By mainly analyzing interviews with the two students, Cheng (2014) identified four themes in the two doctoral researchers' writing process: "learning how to play", "following or bending the rules", "deciding whether to play", and "identifying who to cite in the grant proposals". The fact that one student eventually succeeded in obtaining grant funding whereas the other did not was tentatively attributed to the presence or absence of seasoned researchers who could guide the student in the writing process. Overall, the study showed the importance of the agentive role students play in negotiating through the grant genre system during their transition from the coursework to the dissertation stage of their graduate training.

Lastly, unlike the studies above which examined texts to some degree, Cadman (2002) focuses exclusively on the "context of situation relating to the research proposal as a definable genre" (90), instead of the text itself. Cadman (2002) surveyed faculty supervisors across various disciplines in an Australia university, asking them to prioritize the particular features they expected in a successful student research proposal. Some of the features uncovered include: "feasibility", " updated knowledge of the field ", and "appropriateness of methodology". In addition, the study reveals that the "discoursally constructed self" was considered more important than the substantive content of the proposal itself.

These studies, with their different approaches to the research proposal, have produced useful insights into this genre, such as the Competence claim and Compliance claim of the EU grant proposals in Connor and Mauranen (1999), Research question and/or hypothesis in Connor (2000), the "game-playing" metaphor in Cheng (2014) and the assessment of "discourse persona" in Cadman (2002). They have advanced our understanding of both the textual and contextual aspects of this genre and also provided a rough schema for the present study. Nonetheless, our knowledge of the research proposal is still in its infancy. Not excepting Cadman (2002), there are currently no genre investigations of student-written research proposals for purposes of gaining entry into graduate programs. The present study aims to fill the gap by adopting an integrative approach that combines textual and contextual analyses of student written research proposals.

\section{Method}

\section{Textual data}

The three research proposals for this study were collected from three research students in 2006. They were at varying stages of pursuing a research degree in applied linguistics at a leading Singapore university where the working language is English (see Table 2 for author information). The proposals that participants provided are those that they had submitted when applying to the research programs to which they were eventually accepted. The respective authors signed consent forms to take part in the research project and their proposals are coded as P1, P2 and P3 in this paper.

\section{Interview data}

Interviews were conducted with the three authors for two purposes. One was to confirm with them the accuracy of the labeling of rhetorical moves/strategies. During the 
Table 2 Information on research proposals and authors

\begin{tabular}{llll}
\hline & P1 & P2 & P3 \\
\hline Student Origin & Malaysia & Philippines & Singapore \\
Year of Admission & 2005 & 2005 & 2005 \\
Program & PhD & PhD & MA-PhD \\
Research Area & Educational Phonology & Critical Discourse Analysis & Critical Discourse Analysis \\
Word Count & 3630 & 2009 & 1459 \\
\hline
\end{tabular}

${ }^{a} \mathrm{MA}-\mathrm{PhD}$ indicates the status of the student who, though initially admitted as an MA student was now in the process of upgrading to $\mathrm{PhD}$ candidature

interview, I checked my analysis and labeling with each author, wherever I had doubts about the rhetorical purpose for a given stretch of texts. Where the authors disagreed with my reading and labeling of their text components, discussion followed to resolve such disagreements and arrive at the most accurate way of labeling each move/strategy. The second purpose of the interview with the authors was to elicit their perceptions on the research proposal as a genre. Questions were designed to elicit their understanding of the overall communicative purpose of the research proposal, its intended readership, prominent features of proposals and the rationale behind specific moves/strategies. In addition, data from an interview conducted with an established faculty member in linguistics research (Prof W) is also reported here. ${ }^{1}$ Prof W was from the Department of English Language and Literature of the University and had a wealth of experience reading research proposals submitted for graduate degree applications. Questions designed for the faculty member were intended to elicit expert expectations and perceptions on the production and evaluation of this genre. $^{2}$

\section{The institutional role of the research proposal}

Historically, the research proposal for graduate degree admission represented part of the older graduate degree program structure at this University which used to adhere to a British style of graduate degree education. This meant that postgraduate programs by research consisted solely of a dissertation with practically no coursework component. In that context, the research proposal used to be a compulsory requirement for admission into the Department's research degree programs. However, Prof $\mathrm{W}$ noted that the submission of a graduate degree research proposal was no longer required for application purposes, as a result of the "Americanization" of the university's curriculum.

Though no longer formally obligatory, research proposals were important for applicants who applied for the competitive university research scholarship where evaluation of the applicant's potential to conduct research became a decisive factor in the admission process. Since most applicants requested scholarship funding, the research proposal was considered a de facto requirement in their application. According to Prof W, the communicative purpose of the research proposal in the context of admission evaluation was generally to see that the applicant was able to construct a research project relevant to the program being applied for. Specifically, he highlighted that faculty members would like to see clear formulation of research questions, display of background knowledge and signs of compatibility to the department's research profile. 


\section{Analytical framework}

The present study follows the Swalesian tradition of rhetorical analysis, specifically the CARS model that was discussed earlier (see Table 1). To reiterate, the essential construct underlying Swales' rhetorical analysis is the "move", defined as "a text segment made up of a bundle of linguistic features, (lexical) meanings, propositional meanings, illocutionary forces, etc., which give the segment a uniform orientation and signal the content of discourse in it" (Nwogu 1997, 114). Within each move, there are further smaller rhetorical units, referred to as "strategies" in this study. The naming of moves and strategies is largely in keeping with existing studies (e.g., Swales 1990; Connor 2000; Yang 2001). However, since CARS and its adaptations (see discussions in the introductory sections) were intended to describe a single section of the RA (i.e., introduction), they cannot fully accommodate the rhetorical structuring of full-length research proposals. Therefore, new moves and strategies have been identified in this study, as will be seen in the results/analysis section below. In addition, following existing practice (Crookes 1986; Holmes 1997), where a sentence/chunk of text seemed to denote more than one rhetorical function, the solution adopted was to assign the most salient rhetorical function to the text.

\section{Results and analysis}

Table 3 summarizes information on move structure, strategies and textual space allocated to each move across the three proposals. Textual space was measured in terms of the number or percentage of sentences for the move/strategy, following existing practice (e.g., Anthony 1999; Ozturk 2007). A sentence is defined here as a main clause with all its associated dependent clauses, and for the purposes of analysis, is identified by orthographical cues (i.e., begins with a capital letter and ends with a full stop, Aarts 2014). Tables 4, 5 and 6 present the individual move sequence of the three proposals. In the analysis below, I focus on the prominent trends and contrasts observed across the three texts in terms of the use of rhetorical moves or strategies, while acknowledging that not all variations can receive a satisfactory explanation, given existing literature pointing to both inter- and intra-disciplinary variations in the generic structure of academic texts (e.g., computer engineering, Anthony 1999; applied linguistics, Ozturk 2007; environmental science, Samraj 2002). Most importantly, this is an exploratory study with a small corpus size, and attempting to remark on all aspects of rhetorical patterns in the three texts would seem to risk inappropriate generalization. Consequently, only the prominent trends and contrasts will be focused on.

With this caveat in mind, an examination of Table 3 in terms of allocation of textual space reveals Move 1 and Move 3 to be relatively important rhetorical components: the average textual space for Move 1 (Establishing a territory) across the three proposals is $46 \%$ on average, and for Move 3 (Occupying the niche), $21 \%$. They constitute the two moves that take up the most space $(67 \%)$ in the three proposals. The textual prominence of Move 1 (Establishing a territory) is probably due to the importance and indispensability in displaying knowledge about the field.

Both published resources and the specialist informant in this study highlighted the importance of demonstrating familiarity with existing literature in the research proposal. In Allison (2002) for examples, prospective graduate degree applicants are advised to justify their proposed research by referring to existing knowledge, belief, or 
Table 3 Moves and relative textual space across three proposals

\begin{tabular}{|c|c|c|c|c|c|}
\hline \multirow[t]{2}{*}{ Moves } & & \multicolumn{4}{|c|}{ Textual space of move } \\
\hline & & $\overline{\mathrm{P} 1}$ & $\mathrm{P} 2$ & P3 & $\overline{A v g}$ \\
\hline Move 1 & Establishing a territory & $27 \%$ & $32 \%$ & $80 \%$ & $46 \%$ \\
\hline Strategy 1 & $\begin{array}{l}\text { Claiming centrality } \\
\text { and/or }\end{array}$ & - & 5 & 2 & \\
\hline Strategy 2 & Making topic generalizations & - & 3 & 7 & \\
\hline Strategy 3 & Reviewing items of previous research & 34 & - & 35 & \\
\hline Strategy 4 & Stating personal interest & - & 14 & - & \\
\hline Move 2 & Establishing a niche & $11 \%$ & $16 \%$ & $0 \%$ & $9 \%$ \\
\hline Strategy 1 & Indicating a gap & 14 & 11 & - & \\
\hline Move 3 & Occupying the niche & $17 \%$ & $30 \%$ & $16 \%$ & $21 \%$ \\
\hline Strategy 1 & Outlining purposes & 14 & 17 & 9 & \\
\hline Strategy 2 & Spelling out contribution/significance of proposed research & 8 & 4 & - & \\
\hline Move 4 & Establishing theoretical basis & $9 \%$ & $0 \%$ & $0 \%$ & $3 \%$ \\
\hline Strategy 1 & Reviewing literature relevant to theory & 1 & - & - & \\
\hline Strategy 2 & Defining theory & 2 & - & - & \\
\hline Strategy 3 & Explaining theory & 9 & - & - & \\
\hline Move 5 & Spelling out methodology & $34 \%$ & $12 \%$ & $2 \%$ & $16 \%$ \\
\hline Strategy 1 & Delimiting the scope of study & 2 & - & - & \\
\hline Strategy 2 & Defining terms & 10 & - & - & \\
\hline Strategy 3 & Describing data & - & 1 & - & \\
\hline Strategy 4 & Describing subjects & 10 & - & - & \\
\hline Strategy 5 & Describing experiment & 12 & - & - & \\
\hline Strategy 6 & Describing analytical procedure & 9 & 6 & - & \\
\hline Strategy 7 & Indicating analytical framework & - & 1 & 1 & \\
\hline Move 6 & Achieving closure & $2 \%$ & $10 \%$ & $2 \%$ & $4.7 \%$ \\
\hline Strategy 1 & Reiterating purpose & - & 1 & 1 & \\
\hline Strategy 2 & Restating significance of proposed research & - & 6 & - & \\
\hline Strategy 3 & Indicating limitation of proposed research & 3 & - & - & \\
\hline
\end{tabular}

${ }^{\text {a }}$ The relationship between all strategies within moves in the present study is and/or

practice, including relevant research that already exists on the topic (222). Prof W likewise remarked that the applicant needed to demonstrate an understanding of the current state of art. It is therefore not surprising that, on average, Move 1 (Establishing a territory) occupies a proportionally large rhetorical space. Nevertheless, there is a noticeable difference between P3 (with $80 \%$ of textual space devoted to Move 1) and the remaining two proposals ( $27 \%$ for P1 and $32 \%$ for P2). The first point to note is that, as already alluded to above, variation exists even within a single discipline in terms of rhetorical structure (e.g., Anthony 1999; Connor 2000; Samraj 2002; Ozturk 2007). For instance, one biology proposal studied in Connor (2000) contained $3.01 \%$ of textual space for Move 1 (termed Territory in Connor 2000) compared with another biology proposal with $16.2 \%$ of textual space for the same move. In the case of P3 in this study, the high percentage of textual space for Move 1 may have to do with the interdisciplinary topic being proposed which has to do with the linguistic construction of women in crime reports, a topic that encompasses several areas of study, including language, 
Table 4 Move sequence of P1

\begin{tabular}{|c|c|}
\hline \multicolumn{2}{|c|}{ Move sequence of $\mathrm{P} 1$} \\
\hline \multirow[t]{2}{*}{ Move 1} & Establishing a territory \\
\hline & Reviewing items of previous research (1 sentence) \\
\hline \multirow[t]{5}{*}{ Move 2} & Establishing a niche \\
\hline & Indicating a gap in research world (3 sentences) \\
\hline & Indicating a gap in real world (5 sentences) \\
\hline & Indicating a gap in research (1 sentences) \\
\hline & Indicating a gap in real world (1 sentence) \\
\hline \multirow[t]{7}{*}{ Move 4} & Establishing theoretical basis \\
\hline & Reviewing literature relevant to theory (1sentence) \\
\hline & Explaining theory (2 sentences) \\
\hline & Defining theory (1 sentence) \\
\hline & Explaining theory (5 sentences) \\
\hline & Defining theory (1 sentence) \\
\hline & Explaining theory (2 sentences) \\
\hline \multirow[t]{2}{*}{ Move 1} & Establishing a territory \\
\hline & Reviewing items of previous research (33 sentences) \\
\hline \multirow[t]{2}{*}{ Move 2} & Establishing a niche \\
\hline & Indicating a gap in research world (2 sentences) \\
\hline \multirow[t]{3}{*}{ Move 3} & Occupying the niche \\
\hline & Spelling out significance of research to real world (1 sentence) \\
\hline & Outlining purposes (14 sentences) \\
\hline \multirow[t]{3}{*}{ Move 5} & Spelling out methodology \\
\hline & Delimiting scope of study (2 sentences) \\
\hline & Describing subjects (4 sentences) \\
\hline \multirow[t]{2}{*}{ Move 3} & Occupying the niche \\
\hline & Spelling out contribution/significance of research (7 sentences) \\
\hline \multirow[t]{6}{*}{ Move 5} & Spelling out methodology \\
\hline & Defining terms (10 sentences) \\
\hline & Describing subjects (6 sentences) \\
\hline & Describing experiment (1 sentence) \\
\hline & Describing analytical procedure (9 sentences) \\
\hline & Describing experiment (11 sentences) \\
\hline \multirow[t]{2}{*}{ Move 6} & Achieving closure \\
\hline & Indicating limitation (3 sentences) \\
\hline
\end{tabular}

ideology, media, gender, and criminology. Indeed, it has been suggested that researchers working on interdisciplinary topics tend to provide more theoretical background to help the reader become familiar with "related or parent disciplines about the issues investigated" (Ozturk 2007, 34).

Therefore, the author of P3 felt it necessary to provide a comprehensive overview of all relevant fields in the proposal, resulting in a substantial literature review section. Also, P3 is the shortest proposal in the data set, containing fewer than 1500 words, and it has been shown that shorter texts tend to contain proportionally more text for establishing territory (Connor 2000). 
Table 5 Move sequence of $\mathrm{P} 2$

\begin{tabular}{|c|c|}
\hline \multicolumn{2}{|c|}{ Move sequence of $\mathrm{P} 2$} \\
\hline \multirow[t]{3}{*}{ Move 1} & Establishing a territory \\
\hline & Stating broad personal interest (1sentence) \\
\hline & Stating specific personal interest (3 sentences) \\
\hline \multirow[t]{2}{*}{ Move 3} & Occupying the niche \\
\hline & Outlining purposes (4 sentences) \\
\hline \multirow[t]{5}{*}{ Move 1} & Establishing a territory \\
\hline & Making topic generalizations (1 sentence) \\
\hline & Claiming centrality (1 sentence) \\
\hline & Making topic generalizations (2 sentences) \\
\hline & Stating personal interest ( 6 sentences) \\
\hline \multirow[t]{2}{*}{ Move 2} & Establishing a niche \\
\hline & Establishing a niche: indicating a gap (3 sentences) \\
\hline \multirow[t]{2}{*}{ Move 3} & Occupying the niche \\
\hline & Spelling out contribution/ significance of proposed research (3 sentences) \\
\hline \multirow[t]{2}{*}{ Move 2} & Establishing a niche \\
\hline & Indicating a gap (3 sentences) \\
\hline \multirow[t]{3}{*}{ Move 3} & Occupying the niche \\
\hline & Spelling out contribution/ significance of proposed research (1 sentence) \\
\hline & Outlining purposes (2 sentences) \\
\hline \multirow[t]{2}{*}{ Move 1} & Establishing a territory \\
\hline & Stating personal interest (4 sentences) \\
\hline \multirow[t]{2}{*}{ Move 2} & Establishing a niche \\
\hline & Indicating a gap (5 sentences) \\
\hline \multirow[t]{2}{*}{ Move 1} & Establishing a territory \\
\hline & Claiming centrality (4 sentences) \\
\hline \multirow[t]{4}{*}{ Move 5} & Spelling out methodology \\
\hline & Indicating analytical framework (1 sentence) \\
\hline & Describe data (1 sentence) \\
\hline & Describing analytical procedure (6 sentences) \\
\hline \multirow[t]{2}{*}{ Move 3} & Occupying the niche \\
\hline & Outlining purposes (research questions) (11 sentences) \\
\hline \multirow[t]{3}{*}{ Move 6} & Achieving closure \\
\hline & Reiterating purpose (1 sentence) \\
\hline & Restating significance of proposed research (6 sentences) \\
\hline
\end{tabular}

Despite containing a proportionally large textual space for Move 1 (Establishing a territory), P3 is missing Move 2 (Establishing a niche), in contrast to the other two proposals. This is perhaps not surprising, given existing findings that Move 2 seems to be optional in student written texts especially when the writing is for an immediate target audience (e.g., Soler-Monreal et al. 2011). Namely, when the text is not intended to be highly self-promotional or in need of demonstrating novelty, there is a trend for Move 2 to go missing.

As for Move 3 (Occupying the niche), both the faculty informant and proposal authors agreed that it is extremely important for research proposals to have clear and 
Table 6 Move sequence of P3

\begin{tabular}{ll}
\hline Move sequence of P3 & \\
\hline Move 3 & Occupying the niche \\
Move 1 & Outlining purposes (1 sentence) \\
Move 3 & Establishing a territory \\
& Reviewing items of previous research (3 sentences) \\
Move 1 & Occupying the niche \\
& Outlining purposes (3 sentences) \\
Move 5 & Establishing a territory \\
& Making topic generalizations (4 sentences) \\
Move 3 & Spelling out methodology \\
& Indicating analytical framework (1 sentence) \\
Move 1 & Occupying the niche \\
& Outlining purposes (5 sentences) \\
& Establishing a territory \\
& Reviewing items of previous research (2 sentences) \\
& Claiming centrality (1 sentence) \\
& Reviewing items of previous research (2 sentences) \\
& Claiming centrality (1 sentence) \\
& Reviewing items of previous research (7 sentences) \\
& Making topic generalizations (2 sentences) \\
& Reviewing items of previous research (8 sentences) \\
& Making topic generalizations ( 1 sentence) \\
& Reviewing items of previous research (13 sentences) \\
& Reieving closure \\
&
\end{tabular}

unambiguous research objectives and also to strengthen the statement of purpose by spelling out the significance of the proposed research (Move 3), hence the relatively high proportion of textual space assigned to this move. There is again some variation across the three proposals for this move too. Proportionally, P2 devotes almost twice as much textual space (30 \%) to Move 3 than P1 (17 \%) and P3 (16 \%). The difference between P2 and P1 in the proportion of Move 3 is simply due to the difference in overall length of proposals (the two proposals are comparable in the number of sentences for Move 3; see Table 3). As to the difference between P2 and P3, two proposals of similar length and from the same discipline, I observe that P2 fulfills Move 3, Strategy 1 (Outlining purposes) by not only stating the overall objective, but also in the form of two main questions and seven specific questions, thereby resulting in a substantial Move 3. In comparison, P3 only states the overall objective. In this respect, P3 seems closer to the norm of humanities proposals than $\mathrm{P} 2$, in light of the observation that science disciplines, but not humanities tend to include both objectives and specific questions in their research proposals to occupy a research niche (Connor 2000).

Apart from the textual space devoted to particular moves/strategies, the absence of certain rhetorical components also deserves attention. For example, Strategy 3 of Move 1 , Reviewing items of previous research is not present in P2. Although the author does make some general remarks regarding the status of knowledge in the field, the effort to 
specify previous findings and attribute them to specific researchers was not found in this proposal. Considering the importance of citing peers' work to establish rapport and self-identity in the academic community, the absence of such rhetorical effort in P2 calls for an explanation, which I offer below where I discuss Strategy 3 of Move 1 (Reviewing items of previous research).

Spelling out methodology (Move 5) is another site where variation occurs across the three proposals. P1 seems to set itself apart from the other two proposals in having quite a detailed methodology move, making use of five rhetorical strategies. P2 contains a methodology section, but its rhetorical realization is not as complex, amounting to three strategies. Lastly, P3 contains only one strategy (Indicating analytical framework) in this move. The contrast between P1, on the one hand, and P2 and P3, on the other, could be attributed to the differences in the mode of enquiry in the research subfields. Namely, P1 is concerned with educational phonology. As a field that combines educational studies and phonetics, two areas that rely on well designed experiments to elicit research data, the writer has to present a rather detailed methodology section in the proposal to convince the reader that she does have a viable research design. In comparison, Critical Discourse Analysis (CDA), the research area of P2 and P3, being a non-experimental field, relies more on problematizing issues in society and their reflection in discourse than in executing any experiment or defining any variables, which accounts for the lower textual emphasis given to the methodology move in these two proposals ${ }^{4}$ (P2 and P3).

Having observed the distribution of moves in the three research proposals and explaining the prominent trends, the sections below offer a detailed description of and explanation for the realization of strategies.

\section{Establishing a territory}

Establishing a territory is a move in the research proposal that maps out the general research area in which the proposed research is located. It sets up the larger intellectual or real world background for the proposed topic via the use of four mutually inclusive strategies: Claiming centrality, Making topic generalizations, Reviewing items of previous research, and Stating personal interest. The first three strategies are from the CARS model (see Table 1). The last was formulated specifically for this study. The four strategies can occur together or independently as Tables 4, 5 and 6 show.

\section{Claiming centrality}

According to Swales (1990), one rhetorical vehicle to establish a research territory is the centrality claim. This is a strategy where the author "makes appeals to the discourse community whereby members are asked to accept that the research about to be reported is part of a lively, significant or well-established research area" (Swales 1990, 142). Centrality claims are signaled by such lexical items and their variants as "important", "central", "interesting" and "indispensable". Centrality claims were found in P2 and P3, as shown by examples (1) and (2) below (emphases in all examples are mine): 
(2)

...I think it is significant and worthwhile (imperative even for somebody like me who ...) to make explicit this relationship and show how the most "natural" and "common-sensical" of discourses are ... and potential harm if their assumptions are not questioned or challenged (P2)

In both examples, the authors assert the importance of their proposed research by using the positive evaluative words such as "important", "powerful", "significant", "worthwhile" and "imperative", thereby attempting to convince the reader that the research field is justified on account of its prominence. In addition, P2 also highlights the negative consequences ("potential harm") in the event that the current status quo is allowed to continue, thereby indirectly conveying the importance of the proposed topic.

\section{Making topic generalizations}

A second rhetorical device used for territory establishing, according to Swales (1990), involves making topic generalizations about the field. This is a neutral statement where the writer expresses "in general terms the current state of the art - of knowledge, of technique..." (Swales 1990, 146). Following Samraj (2002), a further distinction is made between topic generalizations in the research world as opposed to the real world, which can be seen in examples (3) and (4) respectively.

(3) Making generalization in research:

For the most part, I subscribe to its main tenet that there is a ..., that any use of language is informed or influenced by..., that language and one's use of it are always ideological. (P2)

(4) Making generalization in real world:

Singapore is an Asian society strongly grounded in its eastern values. ....Marriage is seen as a partnership where the woman serves the husband, is a mother and caregiver to the children and is a comfort provider for the home. These constructs of women lie within the ideology of patriarchy. (P3)

The bolded phrase "main tenet" in (3) serves as a lexical signal that what follows is a description of the beliefs and practices in the field being proposed for study. In the subsequent three parallel that-clauses, the writer spells out the basic theoretical underpinnings that constitute her proposed field - CDA. In (4), the author is not so much referring to the status of knowledge in the field but rather making generalizations on the social conditions surrounding the subjects she wishes to analyze. Throughout the two examples, words such as "be" and "lie", known as relational processes in Systemic Functional Linguistics and which are usually used to denote incontestable truths, serve to remind the reader that topic generalizations are being made, either about the research world or about the real world. 


\section{Reviewing items of previous research}

Reviewing items of previous research is a rhetorical device where writers specify previous findings, attribute the findings to their authors, and adopt a stance towards the findings (Swales 1990). It is an important rhetorical strategy in the sense that this is the place where writers demonstrates their familiarity with the field and also seek to establish rapport and self-identity within the community by citing peers' works. Two proposals (P1 and P3) make use of this strategy (see Table 3). Indeed, it is the opening sentence in P1 (see Table 4):

Jenkins $(2002,195)$ calls for a major reconsideration of the way in which pronunciation is currently dealt with, not only in L2 English classrooms but also in phonology teacher education and in research. (P1)

By referring to a recognized expert, the author conveys the message that her proposed area is relevant because even experts are emphatically demanding work to fix this particular issue in the field. By doing so, the author maps out the terrain for her research. Reviewing items of previous research is a strategy used by P3 as well, though not in the initial position of the proposal. This strategy seems to feature rather prominently in terms of textual space in the two proposals that employ it: 27 and $64 \%$ of sentence count in P1 and P3 respectively.

Curiously this strategy seems to go completely missing in P2. Although the author does make some mention of the current status of knowledge in the field, the attempt to cite specific research is absent in P2. Generally, scholars would view the lack of this rhetorical feature in a negative light, as indicated by the comment made by Prof W in the interview:

“...it (lack of reference to literature) would be bad, right? I mean, this is postgraduate work; so you need to indicate some awareness or at least some attempt in trying to understand what is going on in terms of the current state of art"

P2 author explained that she was pressed for time and therefore was not able to include a detailed literature review in the proposal. Interestingly, the author also indicated that she did not think it was important to cite relevant works in the proposal and that showing a basic understanding of the field would be sufficient ${ }^{5}$, a comment that seems to reveal some discrepancy between this student's perceptions of research proposals and faculty's expectations. When pressed on this point, Prof W noted that the Department reviewed an application in its totality, and that other factors such as grades and reference letters might be able to make up for possible deficiencies in research proposals. Future research on occluded genres should therefore look into examining a cluster of text types (e.g., research proposals, personal essays, reference letters) to understand how they might interact and complement with each other in these relatively high-stakes situations.

\section{Stating personal interest}

This study has identified a new strategy to realize Move 1 in graduate degree research proposals: Stating personal interest. This is the place where the author explicitly 
expresses his/her own interest in the proposed subject and by doing so introduces the field into the discourse. This is different from the Claiming centrality strategy which points to the research community as being collectively interested in the proposed subject. Examples of Stating personal interest are shown below in examples (7) and (8):

For years now, I have been interested in the notions of female identity, subjectivity, and agency ... (P2)

(8)

I am particularly concerned with the workings of language in these discourses...

More to the point, I am interested in the connection between discursive change and social change ... In the end, I'd like to see how female identity has been

transcribed, ... (P2)

It is interesting that the author resorted to personal interest to carve out a research territory in applied linguistics, given the façade of scientific research generally being impersonal and detached. On expressing interest in developing a research proposal, Allison $(2002,166)$ notes that evidence of a researcher's expressed interest could be "positive" in an proposal for small scale projects but he cautions that a personal interest would "not be sufficient in itself to justify admitting a student to a higher degree by research". Perhaps there are two reasons for the occurrence of such a strategy in P2 that had been accepted into a $\mathrm{PhD}$ program. First, statement of personal interest in P2 is complemented by the avowed potential contribution of the proposed research to the current state of knowledge, thereby making the proposed research relevant to the larger academic community as well. As will be shown below, P2 makes use of Strategy 2 of Move 3 (Spelling out contribution/ significance of proposed research), whereby the author argues that among other things, her proposed research will attempt to address the structural limitations of CDA. Fusing personal interest with potential contribution to knowledge is desirable, as remarked by Prof W: "... you need to say that, why your personal interest is worth translating into an actual research project is because it is also relevant to on-going debates or issues". Second, as revealed during the interview, the author of the proposal said she wished to foreground the sustainability of the proposed research arising from her strong interest in the topic:

“...if I am not interested in it, I don't think I will be able to do it. I mean, given, for instance, the extent of $\mathrm{PhD}$..., one could be spending a few years dealing with the same thing. I think you have to be personally invested in it before you can actually start doing it..."

Having examined Move 1, Establishing a territory, I now turn to Move 2, Establishing a niche.

\section{Establishing a niche}

Establishing a niche is the move where the author, after having identified a general research area, goes on to lay the rhetorical foundation for the research to be announced 
or presented. Such foundation work can be achieved using any of the four strategies suggested in the CARS model, namely, Counter-claiming, Indicating a gap, Questionraising or Continuing a tradition.

As shown in Table 3, two of the three proposals (P1 and P2) utilized the niche establishing move. Although the CARS model identifies four strategies for the Establishing niche move, I observe only one strategy in my data, namely Indicating a gap. This confirms previous research where Indicating a gap was found to be the most common strategy used to realize Move 2 (e.g., Chin 1993) possibly because it sounds less confrontational to academic reviewers than other possible options, say, bluntly countering a previous claim.

For the Indicating a gap strategy, this study makes a distinction between a real-world gap and a gap in research, following Samraj (2002). P1, a proposal on educational phonology, makes use of both types of gaps. The proposed research is supposed to fix a real world problem (namely, current classroom instruction) and at the same time, add to the understanding of research in phonology pedagogy; hence, the occurrence of the two types of gap indication. P2, a proposal on CDA however, contains only an indication of a gap in research. This is interesting, given that CDA does seek to solve realworld problems relating to power and ideology. An example of a real-world gap in P1, and an example of a gap in research are provided below in (9) and (10):

In the Malaysian school curriculum very little attention is paid to the teaching of pronunciation as ... (Rajadurai, 2001). (P1)

...in CDA which proposes history as a helpful framework in the study of language, diachronic studies are still underrepresented... Much of CDA continues to be synchronic ... (P2)

Most gap-indicating, either in the real world or in research, is signaled by negative or quasi-negative quantifiers (Swales 1990) such as the bolded "little" in (9). In (10), the adjective "underrepresented" serves to indicate a gap in research. In addition, the bolded verb "continue" serves to remind the reader that despite the presence of problems, the research community has yet to fix these problems, thereby justifying the proposed research. I found that most signals of gap indicating are neutral ("little", "few", "however", "under-represented", "continue to"...), as opposed to potentially confrontational signals via the use of negation words such as "not", "rarely" and "ill" as noted by Swales (1990). The fact that the writers in this study have refrained from using such highly confrontational gap-signaling could be interpreted as an effort to sound duly cautious, especially so as an academic apprentice who has yet to acquire membership in the community in order to speak authoritatively.

\section{Occupying the niche}

Occupying the niche is the third move in Swales' CARS model. Its rhetorical function is to "turn the niche established in Move 2 into a research space that justifies the present article" (Swales 1990, 159). Typically, this move is realized by three strategies, with two 
further sub-categorizations within Strategy 1 (1A and 1B). The strategies are: Strategy 1A: Outlining purpose, where "the author or authors indicate their main purpose or purposes" (Swales 1990, 159); Strategy 1B: Announcing present research where "the author or authors describe what they consider to be the main features of their research" (Swales 1990, 159); Strategy 2: Announcing principal findings where the main findings of the research are presented; and, Strategy 3: Indicating $R A$ structure, where the RA structure is presented for an overview of the content of the whole article. Strategies 2 and 3 are only relevant to published articles and therefore, are not found in my data, consisting of research proposals with ideas about research yet to be executed. In addition, one new strategy for Occupying the niche is found in my data, which is labeled: Spelling out contribution/significance of proposed research, where the author talks about the potential worth of the proposed research.

In terms of the sequence of Move 3 in relation to the other moves, it is observed that in P2 (see Table 5), two out of four times, Move 3 (Occupying the niche) follows Move 2 (Establishing a niche). Researchers elsewhere have noted such a "slot-and-filler" relationship between Move 2 and Move 3 (e.g., Swales 1990; Connor 2000). This relationship is also attested in the present study. Below, I discuss in more detail the two strategies of Move 3 in the research proposals: Outlining purposes and Spelling out contribution/significance of proposed research.

\section{Outlining purposes}

As shown in Table 3, 4, 5 and 6, Outlining purposes is characterized by its obligatory presence, a tendency to occur early and also to recur. All three proposals make use of this strategy, thus offering grounds to postulate its obligatory presence in research proposals generally. In terms of the position of this strategy, there is a trend to foreground Outlining purposes in both P2 and P3. In P2, this strategy initially occurs in the fifth sentence of the proposal. P3 emphasizes this strategy even more, by placing it in the very first sentence of the research proposal. Besides the relatively early positioning of this strategy, I also noted its recursion. In both P2 and P3, this strategy occurs three times (see Tables 5 and 6). In addition, in both P1 and P2, Outlining purposes occurs as an independent section, titled "Objectives of Study" and "Preliminary Research Questions" respectively.

The obligatory presence, early positioning, recursion and clear sectional signaling of the Outlining purposes strategy observed in the proposals point to a rhetorical prominence assigned to this strategy. The foregrounding of this strategy is very likely a generic characteristic of research proposals in that a graduate degree research proposal serves, above all, to inform future supervisors and the admission board of the research being proposed. Supervisors are most concerned about whether the student researcher has a viable research question to pursue (Cadman 2002), a concern shared by the specialist informant in the present study. As Prof W remarked:

"... I think the student needs to make sure that $\mathrm{s} /$ he has a clear sense of what kind of questions they want to answer... I think this (research purpose/question) is the most important thing. Whether the answer itself is satisfactory or appropriate, correct, or whatever, this is of course something which will be evaluated later on, but if the student does not have a clear idea of what kind of questions he is trying to grapple with, then there is a problem...” 
Two of the proposal writers likewise mentioned that they consider getting their research purpose/objective across as the most important element in constructing a research proposal. Examples (11) - (13) illustrate the Outlining purposes strategies from my data:

...I am particularly concerned with the identities, subjectivities, and agencies ...To show the connection between discursive change on the one hand and social change on the other, I would like to propose a diachronic study, which will cover roughly ten years of policy making as engaged in, and/or initiated or challenged by the CATW. (P2)

The broader concern of this study is with how sociocultural ideologies are constructed and maintained in the mass media...(P3)

The specific concern of this study is to determine whether women's representation and construction in the Straits Times, Singapore's oldest newspaper, are congruent to the ideologically determined roles of women in Singapore (P3)

The word "concern", the purposive infinitive phrase "to show the connection..." and the deictic "this" as in "this study" are clear indications that the writers of P2 and P3 are about to announce the purpose of the proposed research. In addition, when this strategy is repeated in P3 (12 and 13), the specificity in terms of content increases, as indicated by the adjective "specific" (13) and the more complex propositions expressed than those in the first appearance of Outlining purposes in P3.

\section{Spelling out contribution/significance of proposed research}

This strategy sets out to persuade the reader that the proposed research can make a contribution or be of significance to the research community. This strategy is found in P1 and P2, as shown in Table 3. Its appearance deserves comment and explanation since previous researchers (e.g., Allison 2002) have found this rhetorical strategy to be quite visible in proposal writing. The following examples are instances of this strategy in my data:

The findings from this research will be especially beneficial to curriculum designers, ... It is hoped that this study will provide insights into the nature of ILT, ...Eventually, the study hopes to make suggestions on the improvement on.... (P1)

I would like to see, ... how my own study would perhaps challenge it. Maybe, what I actually fear is that in the end, after CDA, after having identified and made sense of these notions of identity, subjectivity, and agency in discourse, I will be left with once again only discourse and no real possibility of changing it or getting out of 
it. My study, therefore, hopes to engage with CDA's notion of discourse, that which not only locates language in its sociopolitical context, but also which provides it

with a conceptually more powerful theorization that inscribes in it the possibility of change while, at the same, defining its structural limitations. (P3)

In these examples, lexical signals for this strategy include "beneficial to...", "provide insight into...", "make suggestion on...", "challenge...", and "provide... with more powerful theorization". In (15), the author first announces her intention to "challenge" the subjectivity in CDA, which could be construed as a proposed contribution to the field. However, note how the challenge is made with a modal adverb "perhaps", which tones down what might otherwise be perceived as a presumptuous aim, since challenging an existing research paradigm is no small enterprise. In the next sentence, the writer acknowledges the formidable task she has set for herself, and admits there might be "no real possibility of changing it or getting out of it". After acknowledging the possible negative outcome, she nonetheless re-asserts the significance of her proposed research, which, to sum it up, is to "provide (CDA) with a conceptually more powerful theorization" and also to "define its structural limitations". It would seem that when authors highlight the potential contribution of their proposed research, they might do so with much qualification so as not to sound too ambitious and to avoid the risk of offending expert members of the community. Such a rhetorical strategy could be construed as a reflection of the writer's awareness of the sensitivities and expectations of the academic community. Insofar as research students are still apprentices yet to be inducted into the academic community and the proposed research has not been put to the test of actual execution, it is important to be cautious when advancing claims on proposed research.

\section{Establishing theoretical basis}

I now turn to the fourth move identified in the proposals: Establishing theoretical basis, as shown in Table 3. The main purpose of this move is to "explicate the theories on which the proposed research is based" (Yang 2001, 86). Of the three proposals, only P1 showed this move, which is not surprising since it is more relevant to experimentbased fields. This move seems to be realized by three strategies, namely, Reviewing literature relevant to theory, Defining theory and Explaining theory. The development and sequencing of such rhetorical strategies is found in Table 5, which details the move/ strategy sequence in P1. In terms of textual space, the strategy of Explaining theory occupies more textual space than the other two strategies. In terms of move development, there is a cyclic pattern here where strategy 2 and strategy 3 tend to recur together. This is because more than one theory is being provided. Therefore, repeated patterns of definition and explanation are necessary to provide clear and adequate ground for the theories being adopted in the proposed research.

In Yang's (2001) analysis of published RAs, she found other rhetorical elements in this section as well, such as Evaluating theory and Relating theory and proposed research. These rhetorical elements are missing from P1. The discrepancy between Yang's observation and my data can be explained on the grounds that Yang examined published RAs whose authors command more rhetorical diversity and force than the author in the present study, who are apprentices, yet to be initiated into the community and who may therefore not have command of the full range of rhetorical capabilities. 


\section{Spelling out methodology}

In this move, the authors discuss in varying details, the planned procedures for data collection, analysis and interpretation. This move was found in all three proposals. There were altogether seven strategies found within this move: Delimiting the scope of study, Defining terms, Describing data, Describing subjects, Describing experiment, Describing analytical procedure and Indicating analytical framework. The distribution and textual space assigned to those strategies can be found in Table 3. As shown in Table 3, P1 uses significantly more Move 5 strategies than P2 and P3 (5: 3: 1), likely because P1 involves an experiment and thus needs to include such extra information as subject selection and experimental procedures. Below I describe the seven strategies in detail.

The first strategy in Spelling out methodology is Delimiting the scope of study, where the author unambiguously states the specific variable, among many possible others, that she intends to examine, as shown in (16)

This study will only look at the phonological factors that affect intelligibility as opposed to factors that are related to grammar and lexis... (P1)

As the example shows, there are other competing factors that could contribute to the problem the author intends to investigate. Therefore, it is important that irrelevant factors be ruled out to bring out the focus of study. The bolded adverb "only" is a lexical signal that the author is narrowing down the research variable.

Defining terms is a strategy found in P1 where all the important terms and concepts used in the proposal are defined and explained. Some instances of Defining terms appear in (17)

...Intelligibility refers to the production and recognition of the formal properties of words and utterances and the ability to produce and receive phonological form... (P1)

... NNS refers to non-native speakers of English with a 'reasonable competence' in English ... (P1)

As revealed during the interview with the author of P1, the employment of this strategy is related to the state of affairs in the proposed field where one term could be used in different senses. By explicitly stating the meanings of technical terms used in the proposed research, the author avoids unnecessary ambiguity/confusion surrounding usage of terminology, which will likely translate into a more positive evaluation of the proposal by potential supervisors or admission board members.

Describing data is a strategy that describes data sources in some detail, wherever possible, thus specifying the scope of data selection as example (18) demonstrates:

My time frame will be from the time CATW first came out with its newsletter (1994) to the present time. (P2) 
Describing subjects provides details with regard to the specifics of subjects for the experiment to be conducted. The difference between Describing data and Describing subjects is that the former applies to non-human sources of data (texts, for example) whereas the latter refers to human participants. Describing subjects is achieved by the author's stating the background of subjects, explicating the criteria and providing justification for subject selection, as the following 2 examples show:

The subjects of this study will be 30 students of various races (Malay, Chinese and Indians) aged between 16 and 17 years of age. (P1)

Subjects will have to be from different classes so that they are not familiar with each other. Subjects will need to have a 'reasonable' competence in English but ... (P1)

Describing experiment is where the author describes in detail the experiment designed in the research proposal. By this strategy, the author not only introduces the experiment procedures but also explains the rationale of the experiment, as example (21) shows.

Subjects will be divided into pairs. Each subject will be required to interact in two conditions, i.e. same L1 and different L1 ...Subjects will be given visual cues. Each pair will ... They will then be instructed to ...

Describing analytical procedure is found in both P1 and P2. It sets out in some detail how the author would treat the data elicited either from experiments and/or discourse in light of the aim of research. While Describing experiment explicates experimental details, Describing analytical procedure is related to post-experiment analysis. Two examples appear below for illustrative purposes:

All interactions ... will be transcribed... However, only sounds that are identified as phonological errors will be transcribed phonetically ...

...Non parametric tests will be carried out ...The tests will be carried out ...This will be to look at the features that are most recurrent in the breakdown of communication between NNS-NNS. (P1)

I will examine how identity, subjectivity, and agency of women in prostitution are constructed and made sense of ...I will also examine... In the end, I'd like to see... 
In the context of this diachronic study, I will look into... Then, I will examine ...On a more global level, I would like to make sense of these constructions vis-à-vis the global issue of trafficking Filipino women. (P2)

Understandably, this move is characterized by the future tense as indicated by the bolded auxiliary "will" across both examples, since it denotes events that will happen after the reference time of the writing. Also, the bolded meta-discourse signals that imply logical sequence such as "also", "in the end", "then", and "on a more global level" are indicative of the procedural details being spelt out.

Indicating analytical framework, the last strategy identified for the move Spelling out methodology, is where the author explicitly states the theoretical framework to be used for the analysis of data, as shown in the following example:

Using a critical linguistic approach (a combined/modified framework based mainly on the works of Michael Halliday, Norman Fairclough and Sara Mills) to analyze the language used in crime reports, I hope to foreground the patriarchal ideologies surrounding women in Singapore. (P3)

By stating the well established models, the author conveys an impression that she is familiar with the existing theories and that her research is not blindly re-inventing the wheel.

\section{Achieving closure}

Two proposals, P1 and P2 contain explicit concluding sections that signal the end of writing, though with varying content and degree of specificity. In terms of the actual section heading used, P1 uses "Limitations" and P2 "Concluding Statement". I have analyzed both section headings as serving the function of bringing closure to the research proposal, and discuss them together under the move labeled Achieving closure. Achieving closure is realized through the use of three strategies: Reiterating purpose, Restating significance of proposed research and Indicating limitation of proposed research, as shown in Table 3.

Restating purpose of proposed research serves to recap and remind the reader of the focus of proposed research, as shown in (25):

Given that female offenders are viewed in their traditional female roles within the study of criminology, this study of language used in media reporting of crimes committed by female offenders should reveal the types of gender attributes and roles assigned to these offenders by society and so uncover the hidden sociocultural ideologies of that society. (P3)

As explained earlier, the importance of having a clear purpose is acknowledged by both the proposal authors and the specialist informant and is reflected textually in terms of the positioning and frequency of the Outlining purposes strategy in Move 3. 
Reiterating this rhetorical content in the concluding section of the proposal represents further evidence that having a clear purpose is the fulcrum around which the whole proposal is constructed.

Restating significance of proposed research is a place where the value of the proposed research is mentioned again, the first time being in Move 3, Strategy 2, as illustrated by (26):

In the end, this research proposal will attempt to do what Critical Discourse Analysis sets out to do... in the hope that such an attempt will work not only toward a more engaging and engaged theorizing of discourse and feminism in the country but also toward a better set of conditions and choices for those for whom all this theorizing is meant. (P2)

This strategy once again puts the proposed research in proper perspective in terms of justification, thus likely increasing the persuasive and rhetorical force of the proposal.

Indicating limitation of proposed research is found in the concluding remarks section of P1. This element has been found in the concluding sections of RAs where reference is usually made to factors such as the size of the sample, an aspect of research that the author tends to have less control over (Yang 2001) rather than any real serious defects in conceptualization or research design. By acknowledging limitations, the author brings balance to the overall argument and also preempts possible criticisms from readers. In P1, this is achieved by indicating the limited focus in research design, as (27) shows:

The focus of this study is on the phonological variations of ILT. Therefore any breakdown in communication by lexical items and/or grammar will not be taken into consideration. The phonological breakdowns that will be considered are only those based on the five features of the Lingua Franca Core as proposed by Jenkins (2000, 2002). (P1)

The exclusion of factors such as lexical items and grammar from analysis is already implied in P1's avowed research aim that examines only the phonological aspect of communication breakdown. One wonders if criticisms would actually be leveled at a research design for excluding areas that the researcher has already declared as outside the focus of study. Staying focused in one's research design is more likely considered a merit rather than a limitation. However, the author chooses to declare her focused aim as a limitation. As revealed by the proposal author during the interview, in this part she is actually indirectly showing her awareness of other research possibilities:

"I know there are other factors that are important. But for my purposes, I can only look at phonological variations and not these two others... This is what I mean by limitation"

Therefore, by showing the "limitation" of her proposed research, the author is restating the focus of her research as well as showing her familiarity with research 
conventions, which might translate into a positive reading of the proposal as one coming from a scholar rhetorically and academically competent.

\section{Conclusion}

Based upon and expanding Swales' (1990) rhetorical analysis, this study has presented a genre investigation of three research proposals submitted to a Singapore-based university for the purposes of securing admission to graduate research programs in applied linguistics. Although textual analysis forms the main part of the study, interviews conducted with both the proposal authors and one faculty member provide valuable insight into the context and expectations for the graduate degree research proposals, thus complementing and enriching the textual analysis.

In addition to those already existing in the CARS model (Table 1), new moves/strategies have been observed in the student written proposals, reflecting both the relevance of the CARS model to my study and the necessity of amendments in order to fully account for the graduate degree research proposal. New moves identified in the data set include Establishing theoretical basis (Move 4), Spelling out methodology (Move 5), and Achieving closure (Move 6). I have explained the occurrence of these moves in terms of the communicative purpose, institutional expectations and disciplinary epistemology.

Looking closely at the moves/strategies, there seems to be a resistance to rigid structuring and categorization of graduate degree research proposals, in terms of the move structure and realizations. In addition, the realization of each move in terms of strategies shows great degrees of latitude in each proposal. The absence of fixed structures in these proposals is not surprising, as flexibility in realization is one key characteristic of the academic genre (e.g., Kwan 2006).

However, the occurrence of certain moves/strategies seems to follow loose trends. For example, it has been observed that Move 2 tends to occur between Move 1 and Move 3, due to the transitional status of Move 2, and the slot-and-filler relationship between Move 2 and Move 3, as has been observed elsewhere (e.g., Chin 1993; Connor 2000). Besides Move 2, Moves 1 and 3 also exhibit some common behavior across the three proposals. These two moves seem to be assigned rhetorical prominence in terms of early positioning, recursion, obligatory presence, and relatively high textual space assigned. The relative textual prominence assigned to Moves 1 and 3 might point to a rhetorical rationale to display familiarity with existing state of the art and also to articulate one's own clear research objectives, both of which seem to be valued in the academic discourse communities, as evidence by comments from the expert informant.

Common to all three proposals is an effort of the author to project a persona of a competent researcher. Such a persona is constructed through the use of moves/strategies related to epistemic knowledge (all three authors), and occasionally also through nonepistemic appeals (P2). The research proposals in this study have attempted to demonstrate the writers' familiarity with literature via the use of Move 1, their ability to carve out a research niche via Move 2, and their ability to formulate research questions by the use of Move 3, which are three elements emphasized in all standard research genres (such as the RA). In addition, the author of P2 resorted to non-epistemic appeals as well, through for example, Stating personal interest to prove the sustainability of one's research topic in terms of strong motivation. However, aware of their status as apprentices, proposal writers 
sound duly cautious when advancing their own claims and indicating gaps in existing research, in order not to sound too bold or arrogant.

The realization of moves in terms of strategies is reflective of disciplinary proclivity as well. Specifically, the use of strategies seems to be conditioned by the concerns of discipline/subfields. In this regard, P1, representing educational phonology, seems to set itself apart from the other two texts. Educational phonology is a field concerned with both real world problems (namely, classroom instruction) and also with theoretical issues in acquisition research. This dual purpose of the discipline predisposes the author of P1 to indicate gaps in both the real world and research world in Move 1; as well as pointing out research contributions to both real and research worlds. In addition, as an experiment-based field, P1 instantiates a much more elaborate Move 5 (methodology) than the other two proposals whose discipline is text-based and interpretation-driven.

The rhetorical structures identified in this study could be used by English for Academic Purposes instructors as examples of possible ways of structuring graduate degree research proposals. Students could benefit from explicit instruction on which elements seem to be valued by faculty members so that they could construct their proposals with this in mind. Most importantly, students could benefit from an explicit understanding of the communicative purpose and faculty expectations of the graduate degree research proposal: to convey a persona of a budding and yet relatively competent researcher with sufficient motivation and focus, to undertake long-term research projects.

\section{Endnotes}

${ }^{1}$ Although two specialist informants were interviewed for this project, one from linguistics and the other literature, I focus on the commentary from the linguistics faculty member here, given the focus of the present paper.

${ }^{2}$ Data collections took place in 2006. Therefore, observations regarding the role of the research proposal in graduate degree admission reflect policies/expectations at that time. As noted in the paper, research proposals were not mandatory for the batch of students in this study. Therefore, no official university documentary requirements existed at that time for the applicants to consult for writing a proposal. The "institutional expectations" laid out in this paper therefore had to rely on interviews with faculty members. The departmental policies of the university in this study have since changed. At present (2016), applicants are required to submit a "Preliminary Research Proposal" of 2000-5000 words. Though the topic of the proposal can be tentative, the applicant must demonstrate "seriousness and ability" through this document. This additional information regarding present institutional expectations is provided here for completeness only. Since such requirements were not in effect at the time of the research conducted for the present study, they will not be commented on or referred to further in the paper.

${ }^{3}$ As shown in the introduction and literature review, such small units were originally called "steps" in the CARS model. However, in keeping with more recent literature (e.g., Kwan 2006), the term "strategy" is used in lieu of "step" in this study. The difference between step and strategy is that the former tends to refer to "obligatory and sequential constituents" of a Move whereas the latter refers to the "non-obligatory and non-sequential constituents" (Kwan 2006, 34). However, as shown in the results/analyses section, none of the constituents simultaneously fulfill the two conditions of 
being "obligatory" and "sequential", to merit the status of "step". Therefore the term Strategy is adopted to label and describe the different realizations of moves in this study.

${ }^{4}$ As an anonymous reviewer pointed out, there is a difference between P2 and P3 in the proportion of text for Move 5, even though they belong to the same field (CDA). While iterating the exploratory nature of the study, and the existence of intradisciplinary variation observed in the genre analysis literature (e.g., Anthony 1999; Connor 2000; Samraj 2002; Ozturk 2007), I also note that the discrepancy here is at least partially due to the method of analysis adopted for this study. It is well known in genre analysis that a sentence/chunk of text may denote more than one rhetorical functions (e.g., Crookes 1986; Holmes 1997; Anthony 1999; Ozturk 2007; Graves, Moghaddasi, and Hashim 2014). As indicated in the section on "Analytical framework", when faced with such situations in the analysis, I followed Crookes (1986) and Holmes (1997) in assigning the most prominent rhetorical function to the sentence/chunk of text. This also consequently means that the secondary rhetorical function is ignored, which explains the depressed proportion of Move 5 in P3. Specifically, some of the text in P3 assigned Move 1 (Establishing a territory) also serves a secondary function of indicating methodology of research (i.e., Move 5). Future research should look into the possibility of accounting for both (or even multiple) functions in a sentence/chunk of text.

${ }^{5}$ I also speculate that the lack of explicit citations in P2 might be due to a lack of access to the most recent literature, which is not uncommon for applicants from developing countries (see Belcher 2007's discussion of problems faced by off-network scholars). While journals may not accept a paper lacking adequate citations, when it comes to research proposals for admission purposes, difficulties in accessing the latest research literature are generally "sympathetically understood" (Allison 2002, 223), but the applicant is still needed to demonstrate a "reasonably good" knowledge of the research field.

\section{Abbreviations}

CARS: Creating a Research Space; CDA: Critical Discourse Analysis; RA: research article

Availability of data and materials

To preserve the anonymity of the participants in the study, their original proposal texts are not provided. However, a complete rhetorical structure analysis of the three proposals is provided in Tables 4, 5 and 6.

\section{Competing interests}

The author declares there are no competing interests, financial or non-financial in the publication of this work.

Received: 2 March 2016 Accepted: 15 June 2016

Published online: 24 June 2016

References

Aarts, Bas. 2014. Sentence. In The Oxford Dictionary of English Grammar, ebook, accessed 25 May 2016 from Oxford Reference Online (Premium) Database.

Allison, Desmond. 2002. Approaching English language research. Singapore: Singapore University Press.

Anthony, Laurence. 1999. Writing research article introductions in software engineering: how accurate is a standard model? IEEE Transactions on Professional Communication 42: 38-46.

Belcher, Diane. 2007. Seeking acceptance in an English-only research world. Journal of Second Language Writing 16: 1-22.

Bhatia, Vijay K. 1993. Analyzing genre: language use in professional settings. New York: Longman.

Bhatia, Vijay K. 2002. A generic view of academic discourse. In Academic discourse, ed. John Flowerdew, 21-39. New York: Longman.

Bunton, David. 2002. Generic moves in PhD thesis introductions. In Academic discourse, ed. John Flowerdew, 57-75. New York: Longman.

Cadman, Kate. 2002. English for academic possibilities: the research proposal as a contested site in postgraduate genre pedagogy. Journal of English for Academic Purposes 1: 85-104. 
Cheng, Ying-Hsueh. 2014. Dissertation grant proposals as 'writing games': An exploratory study of two L2 graduate students' experiences. English for Specific Purposes 36: 74-84.

Chin, Pik Yee. 1993. Genre analysis: research article introductions in particle physics. Master's thesis, National University of Singapore.

Connor, Ulla. 2000. Variation in rhetorical moves in grant proposals of US humanists and scientists. Text 20: 1-28.

Connor, Ulla, and A. Anna Mauranen. 1999. Linguistic analysis of grant proposals: European Union research grants. English for Specific Purposes 18: 47-62.

Crookes, Graham. 1986. Towards a validated analysis of scientific text structure. Applied Linquistics 7: 57-70.

del SazRubio, Ma Milagros. 2011. A pragmatic approach to the macro-structure and metadiscoursal features of research article introductions in the field of Agricultural Sciences. English for Specific Purposes 30: 258-271.

Dudley-Evans, Tony. 1986. Genre analysis: an investigation of the introduction and discussion sections of M.Sc dissertations. In Talking about text, ed. Coulthard Malcolm, 128-145. Birmingham: English Language Research, University of Birmingham.

Feng, Haiying. 2008. A genre-based study of research grant proposals in China. In Contrastive rhetoric: reaching into intercultural rhetoric, ed. Ulla Connor, Ed Nagelhout, and William V. Rozycki, 63-86. Amsterdam: John Benjamins,

Feng, Haiying, and Ling Shi. 2004. Genre analysis of research grant proposals. LSP \& Professional Communication 4: 8-32.

Graves, Heather, Shahin Moghaddasi, and Azirah Hashim. 2014. 'Let G = (V, E) be a graph': turning the abstract into the tangible in introductions in mathematics research articles. English for Specific Purposes 36: 1-11.

Holmes, Richard. 1997. Genre analysis, and the social sciences: an investigation of the structure of research article discussion sections in three disciplines. English for Specific Purposes 16: 321-337.

Hopkins, Andy, and Tony Dudley-Evans. 1988. A genre-based investigation of the discussion sections in articles and dissertations. English for Specific Purposes 7: 113-121.

Hyland, Ken. 1996. Writing without conviction? Hedging in science research articles. Applied Linguistics 17: 433-454

Hyland, Ken. 2000. Disciplinary discourses: social interactions in academic writing. New York: Longman.

Hyland, Ken. 2008. Metadiscourse: exploring interaction in writing. Reprinted. Continuum Discourse Series. London: Continuum.

Kwan, Becky S.C. 2006. The schematic structure of literature reviews in doctoral theses of applied linguistics. English for Specific Purposes 25: 30-55.

Lim, Jason Miin-Hwa. 2012. How do writers establish research niches? A genre-based investigation into management researchers' rhetorical steps and linguistic mechanisms. Journal of English for Academic Purposes 11: 229-245.

Lin, Ling, and Stephen Evans. 2012. Structural patterns in empirical research articles: a cross-disciplinary study. English for Specific Purposes 31: 150-160

Martín, Pedro, and Isabel Karely León Pérez. 2014. Convincing peers of the value of one's research: a genre analysis of rhetorical promotion in academic texts. English for Specific Purposes 34: 1-13.

Myers, Greg. 1990. Writing biology: texts in the social construction of scientific knowledge. Madison: University of Wisconsin Press.

Nwogu, K.N. 1997. The medical research paper: structure and function. English for Specific Purposes 16: 119-138

Ozturk, Ismet. 2007. The textual organisation of research article introductions in applied linguistics: variability within a single discipline. English for Specific Purposes 26: 25-38.

Salager-Meyer, François. 1992. A text-type and move analysis study of verb tense and modality distribution in medical English abstracts. English for Specific Purposes 11: 93-113.

Samraj, Betty. 2002. Introductions in research articles: variations across disciplines. English for Specific Purposes 21(1): 1-17.

Samraj, Betty. 2004. Discourse features of the student-produced academic research paper: variations across disciplinary courses. Journal of English for Academic Purposes 3: 5-22.

Soler-Monreal, Carmen, María Carbonell-Olivares, and Luz Gil-Salom. 2011. A contrastive study of the rhetorical organisation of English and Spanish PhD thesis introductions. English for Specific Purposes 30: 4-17.

Swales, John. 1990. Genre analysis: English in academic and research settings. New York: Cambridge University Press.

Swales, John. 1996. Occluded genres in the academy. In Academic writing: intercultural and textual issues, ed. Eija Ventola and Anna Mauranen, 45-58. Amsterdam; Philadelphia: John Benjamins.

Swales, John, and Christine Feak. 1994. Academic writing for graduate students: essential tasks and skills. Ann Arbor: The University of Michigan Press.

Swales, John, and Christine Feak. 2000. English in today's research world: A writing guide. Ann Arbor: The University of Michigan Press.

Thompson, Geoff, and Yiyun Ye. 1991. Evaluating in the reporting verbs used in academic papers. Applied Linguistics 12: 365-382.

Thompson, Paul. 2009. Literature reviews in applied PhD theses: Evidence and problems. In Academic Evaluation and Review Genres, ed. Ken Hyland and G Giuliana Diani, 50-67. Basingstoke, UK: Palgrave Macmillan.

Williams, lan A. 1996. A contextual study of lexical verbs in two types of medical research reports: clinical and experimental. English for Specific Purposes 15: 175-197.

Yang, Ruiying, and Desmond Allison. 2003. Research articles in applied linguistics: moving from results to conclusions. English for Specific Purposes 22: 365-385.

Yang, Ruiying. 2001. A genre analysis of research articles in applied linguistics. PhD thesis. National University of Singapore.

Zeng, Ya-Jun. 2009. CARS model in analyzing the introduction of research articles: an example from the field of sports science and medicine. US-China Foreign Language: 61-65. 